\title{
Livro ilustrado: texto, imagem e mediação
}

Felícia de Oliveira Fleck

Doutoranda em Ciência da Informação na Universidade Federal de Santa Catarina

Miriam Figueiredo Vieira da Cunha,

Professora do Departamento de Ciência da Informação da Universidade Federal de Santa Catarina

Clarice Fortkamp Caldin

Professora do departamento de Ciência da Informação da Universidade Federal de Santa Catarina

http://dx.doi.org/10.1590/1981-5344/2390

O livro ilustrado abre a perspectiva de diálogo entre texto e imagem, ampliando as experiências de leitura. $O$ objetivo deste artigo é oferecer subsídios teóricos para auxiliar o bibliotecário em suas atividades de mediação de leitura literária com os pequenos leitores, atentando particularmente para o livro ilustrado infantil. Para isso, são apresentadas considerações sobre a literatura infantil $e$ as diferenciações entre o livro ilustrado e o livro com ilustração. Exemplifica-se com uma breve análise de dois livros da produção contemporânea brasileira. Ressalta-se o papel do bibliotecário na apropriação e utilização desse rico material em suas atividades de mediação de leitura literária.

Palavras-chave: Livro ilustrado. Literatura infantil. Mediação de leitura. Bibliotecário.

\section{Picturebook: text, image and mediation}

The picturebook opens the possibility of a dialogue between text and image, enhancing the reading experience. The purpose of this article is to provide theoretical support to assist the librarian in his literary 
reading, mediation activities with young readers, particularly paying attention to the child picturebook. Considerations are made about children's literature and the differences between the picturebook and the book with illustrations. Exemplifies with a brief review of two books of contemporary Brazilian production. We emphasize the librarian's role using this rich material in their literary reading mediation activities.

Keywords: Picturebook. Children's literature. Reading mediation. Librarian.

Recebido em06.04.2015 Aceito em 15.03.2016

\section{Considerações iniciais}

O bibliotecário tem entre suas funções reconhecidas 0 desenvolvimento de práticas de promoção à leitura. Para isso ele precisa ser um mediador de leitura, um leitor experiente capaz de apresentar a outros potenciais leitores o vasto universo dos livros, dos gêneros, dos autores e dos ilustradores. A mediação de leitura nada mais é do que um convite para adentrar esse universo de uma forma prazerosa e envolvente.

Para mediar, segundo Martins (2014, p. 181), é preciso ir além "da percepção cristalizada de mundo no cotidiano e difundida pelos sistemas ideológicos para uma visão crítica da realidade, que tenha em vista a indagação sobre os consensos e a elaboração do pensamento autônomo".

A leitura pode ajudar as pessoas na construção e constituição de si mesmas, a encontrar espaços de liberdade e a partir deles, dar sentido a sua vida. O mediador pode facilitar esse processo, contribuindo para que o leitor se aproprie do texto, o interprete, deslize "sua fantasia, seu desejo, suas angústias" entre as linhas e as mescle com as do autor (PETIT, 2013, p. 27).

Bortolin (2010, p. 115) ressalta que o bibliotecário não pode se esquivar da mediação da leitura, já que o ato de ler precede o ato de se informar, descobrir e investigar. Portanto, a tarefa de mediar a leitura é tão importante quanto a de disponibilizar material bibliográfico aos leitores de uma biblioteca.

Para ser um mediador de leitura, Rasteli e Cavalcante (2013) estabelecem algumas competências, habilidades e atitudes que o bibliotecário deve aprimorar:

ser leitor ativo;

conhecer as teorias da leitura;

valorizar as narrativas orais;

viabilizar o acesso à informação em seus diferentes suportes; 
conhecer as políticas públicas para o livro e a leitura;

estar atento às multiplicidades culturais;

estabelecer relações afetivas com o leitor;

trabalhar em equipe;

estabelecer parcerias;

ter competências aplicadas às TIC;

conhecer e utilizar as ferramentas da Web 2.0;

buscar a educação continuada.

Nessas competências, destacamos a importância do bibliotecário ser um leitor ativo. Além disso, é importante que ele conheça bem a coleção que compõe o acervo da unidade onde atua, pois entendemos que 0 profissional que trabalha com crianças, leitores em desenvolvimento, precisa conhecer a literatura infantil, suas características e particularidades.

Nunca se produziu e vendeu tantos livros infantis e infantojuvenis como na última década no Brasil: são cerca de 1,6 mil lançamentos a cada ano ${ }^{1}$. Trata-se de um vasto material a ser explorado embora nem tudo que é publicado seja de qualidade.

Cabe ao bibliotecário e aos outros profissionais que trabalham em parceria com ele, como os professores, no caso das instituições educativas, escolher livros que possam provocar a imaginação do leitor, refinar seu senso estético e trazer acréscimos à sua experiência de vida e leitura².

Assim, em meio a essa avalanche de títulos, tendo como ponto de partida a leitura literária, é relevante considerar as possibilidades que o livro ilustrado oferece, onde as imagens ampliam e transformam o texto escrito. Hunt (2010, p. 234) acrescenta que as palavras "podem aumentar, contradizer, expandir, ecoar ou interpretar as imagens - e vice-versa". Os livros ilustrados cruzam o limite entre os mundos verbal e pré-verbal e, portanto, podem ser aliados da criança leitora.

O foco desse trabalho é oferecer subsídios teóricos para instrumentalizar o bibliotecário na prática da mediação de leitura literária com os pequenos leitores, atentando particularmente para o livro ilustrado infantil.

Para isso, apresentamos algumas considerações sobre a literatura infantil, buscamos diferenciar o livro ilustrado do livro com ilustração, fazendo uma breve análise de dois livros da produção contemporânea brasileira: "Histórias de recreio" (1982), de Ana Maria Machado, com ilustrações de Llinares e "Vizinho, vizinha" (2002), texto de Roger Mello,

\footnotetext{
1 Dado exposto por Bretas (2012).

2 Para auxiliar essa escolha, esses profissionais podem acompanhar os principais prêmios literários do país concedidos às obras infantis e infanto-juvenis, como o Jabuti, o Barco a vapor e as menções e prêmios da Fundação Nacional do Livro Infantil e Juvenil (FNLIJ).
} 
com ilustrações de Graça Lima, Mariana Massarani e participação especial de Roger Mello.

Dalcin (2012, p. 6) pontua que a participação de ilustradores brasileiros na Feira do Livro de Bolonha a partir dos anos 1990, tornou-se "o propulsor para um novo olhar e uma nova maneira de pensar e fazer literatura infantil no Brasil". A partir daí, novas perspectivas passaram a ser consideradas, desde o objeto livro em si até a composição do projeto gráfico. Em função desse "marco temporal" na forma de se pensar a ilustração dos livros infantis no Brasil, optamos por escolher um livro anterior e outro posterior a esta data, em que se possa perceber com mais clareza as diferenças entre as concepções.

E por fim, ressaltamos o papel do bibliotecário na apropriação e utilização desse material em suas atividades de mediação de leitura literária.

\section{Literatura infantil}

A literatura infantil, por vezes considerada um gênero menor dentro da literatura, passa a ser, cada vez mais, valorizada em seus aspectos poéticos, lúdicos e educativos, não só no ambiente escolar, mas nos espaços de convivência social, cultural e familiar.

Sobre a diferença entre escrever para adultos e crianças, Adélia Prado pontua: "é a mesma diferença entre um vestido para uma velha senhora e para uma menina, feitos do mesmo pano. Os tamanhos são diferentes, mas o corte e a costura exigem o mesmo cuidado" (TAVARES, 2011, n.p.).

Nem sempre se pensou assim. Meireles (1984) destaca algumas características da literatura infantil ao longo da história: a redação escrita das tradições orais; o texto escrito para uma determinada criança que depois passou a uso geral; textos escritos inicialmente para adultos com adaptações posteriores para o público infantil $e$, finalmente, os textos escritos especialmente para as crianças.

Termo de complexa definição, a literatura infantil, é, antes de mais nada, literatura, o que a torna expressão artística por excelência. Como tal, pode ser instrumento de sensibilização da consciência e expansão da capacidade do sujeito de conhecer a si mesmo e o mundo que o cerca.

Meireles (1984, p. 20) pontua que costuma-se classificar como literatura infantil o que para as crianças se escreve. No entanto, talvez o mais acertado fosse classificá-la como o que as crianças leem com interesse e prazer. Ou seja, aqueles textos que combinam arte e beleza (função estética) e que também podem contribuir na formação de valores, na consciência crítica, na percepção de si mesmo e do outro (função educativa).

Na visão de Coelho (2000, p. 46), as grandes obras de literatura infantil ao longo do tempo conciliam as duas funções: estética e educativa. Para ela, a dimensão estética se manifesta quando a obra "provoca emoções, dá prazer, ou diverte, e, acima de tudo, modifica a consciência de mundo de seu leitor". Por outro lado, a dimensão educativa 
se vincula, muitas vezes, a uma intenção pedagógica e, se bem conduzida, pode estimular a criatividade e a descoberta de novos valores.

Conquanto a arte literária possa ser "bela" e "útil" seu valor intrínseco baseia-se, sobretudo, na beleza. É o caráter estético, a linguagem metafórica, os diálogos entre texto e imagem, que transformam um livro para crianças em objeto de desejo e prazer.

Lembram Palo e Oliveira (1998, p. 11, grifo das autoras) que "o pensamento infantil é aquele que está sintonizado com [o] pulsar pelas vias do imaginário" no qual "os projetos mais arrojados de literatura infantil investem, não escamoteando o literário, nem o facilitando"; tais projetos oferecem "os melhores produtos ao repertório, infantil" possibilitando uma "leitura múltipla e diversificada".

Há que se considerar que as crianças são leitores em desenvolvimento e que se relacionam com os livros e com os textos literários de forma diferente dos adultos. Suas vivências e visão de mundo são muito particulares.

Para que interesse à criança, Caldin (2001) afirma que a narrativa deve evitar descrições longas, utilizar o discurso direto, conter um diálogo envolvente com personagens sem complexidades e apresentar um final feliz. E acrescenta, posteriormente, como é interessante aliar ilustrações instigantes e diagramação sedutora à efabulação e ao discurso sintético, a fim de cativar a criança (CALDIN, 2010).

Hunt (2010) complementa que nas primeiras fases de desenvolvimento, as crianças preferem histórias com um elemento de desfecho, ou seja, uma sensação de final. Elas preferem que algo seja resolvido, que a normalidade seja restabelecida, que a segurança seja enfatizada.

Os textos literários infantis devem oferecer múltiplas possibilidades de interpretação e interação, sem trazer conteúdos moralistas ou didáticos, estimulando e desenvolvendo a imaginação. Imaginação esta, que pautada na realidade, faz com que os pequenos possam também criar livremente, trazendo à tona as questões que necessitam compartilhar $e$, de alguma forma, elaborar.

Tendo em vista todas estas questões apresentadas, Hunt (2010, p. 43) elenca alguns motivos pelos quais se deve estudar a literatura infantil:

porque é importante e divertido;

os livros para crianças têm grande influência social e educacional;

são importantes tanto em termos políticos quanto comerciais;

são uma contribuição valiosa à história social, literária e bibliográfica;

são vitais para a alfabetização e a cultura.

A esse respeito já se pronunciava Coelho (2000, p. 17, grifo da autora), ao apresentar a criança "como um ser educável" e ao defender a 
literatura como "um fenômeno de linguagem resultante de uma experiência existencial/social/cultural".

Tanto Coelho (2000) quanto Hunt (2010) estendem o potencial da literatura infantil à formação de conhecimento, muito embora não esqueçam a função lúdica dos textos literários infantis.

Tal função admite, além de narrativa envolvente e sedutora, a presença de ilustrações que materializam o imaginário e comungam com o texto.

\section{Livro ilustrado}

A ilustração pode representar, muitas vezes, a iniciação da visualidade da criança, o seu primeiro contato com a obra de arte e com as artes visuais. Ela tem o papel de formar, de educar o olhar, de ampliar os repertórios visuais, contribuindo na constituição de um leitor crítico não só de textos, mas também de imagens.

Lins (2002, p. 31) acredita que

o texto escrito conta uma história recheada de imagens nas linhas e nas entrelinhas. A imagem complementa e enriquece esta história, a ponto de cada parte de uma imagem poder gerar diversas histórias. O texto e a imagem juntos dão ao leitor o poder de criar na sua cabeça a única história que realmente interessa. A história dele.

Se as relações entre texto e imagem forem bem construídas nos livros infantis, a possibilidade do leitor gerar novas histórias se potencializa.

Para entender essas relações há que se considerar as diferenças entre o livro com ilustração e o livro ilustrado ${ }^{3}$. Embora à primeira vista possam parecer semelhantes, há especificidades que os caracterizam.

O livro com ilustração é aquele em que o texto existe de forma independente, ele sustenta a narrativa, sem a necessidade intrínseca das imagens para que tenha sentido. As ilustrações podem enriquecer a experiência da leitura, mas não são imprescindíveis. Na maioria das vezes elas apenas reproduzem a palavra tal e qual.

No livro ilustrado, também denominado livro álbum ou picturebook, texto e imagem são igualmente importantes, não havendo hierarquização entre escritor e ilustrador, ambos são autores da obra. Assim, a função das palavras é, essencialmente, narrar e a função das ilustrações é descrever ou representar. O caráter ímpar dos livros ilustrados está em combinar e tencionar dois níveis de comunicação: o visual e o verbal (NICOLAJEVA E SCOTT, 2011).

Gili (2014, p. 23) acrescenta que os livros ilustrados atuais "oferecem aos leitores uma experiência de leitura ampla, em que a

\footnotetext{
${ }^{3}$ Denominação pouco conhecida pelo grande público, não há em muitos países um termo único para designar o livro ilustrado infantil: album ou livre d'images (França); álbum ilustrado (Portugal) e em língua inglesa picturebook, picture book e ainda picture-book. No Brasil, o termo foi traduzido como "livro ilustrado", embora ainda seja utilizado sem muito critério e se confunda com "livro com ilustração", ou "livro para criança" (VAN DER LINDEN, 2011).
} 
conjugação de palavra e ilustração pode evocar a realidade sem, no entanto, dela fazer-se retrato".

Ler o livro ilustrado é mais do que ler texto e imagem separadamente. É aguçar o olhar para perceber as nuances e as sutilezas artísticas que se compõem na integração entre as duas linguagens.

Além de texto e imagem, o projeto gráfico é fundamental na concepção do livro ilustrado: há que se atentar para o formato, material, relação entre capa e as guardas, tipo e tamanho da letra, enquadramento e encadeamento do texto e das imagens, disposição e localização das mensagens no suporte. Todas essas características fazem muita diferença no resultado final.

O livro ilustrado é bastante diverso quanto à sua produção, por não possuir uma diagramação regular identificável, como as histórias em quadrinhos, por exemplo. Para Van der Linden (2011, p. 87) as organizações internas do livro ilustrado e as ocupações do suporte "parecem quase infinitas, jogando com o tamanho das mensagens, com seu aspecto formal, com a separação entre elas, com a ocupação da página dupla...".

A diagramação do livro é pensada a serviço da expressão. A partir desse entendimento, o livro ilustrado afirma e consolida o espaço e o status da imagem.

A ilustração é preponderante no livro ilustrado e a ocupação espacial das imagens é superior a do texto escrito, sem contanto, torná-lo secundário.

Com o intuito de clarear as diferenças entre as duas categorias, livro com ilustração e livro ilustrado, apresentamos uma breve análise de duas obras da literatura infantil contemporânea.

O primeiro exemplo é de um livro com ilustração:

Trata-se da obra "Histórias de recreio", escrita por Ana Maria Machado, uma edição da Abril Cultural, de 1982. Ana Maria Machado é considerada pela crítica como uma das mais versáteis e completas escritoras contemporâneas, sendo bastante conhecida por sua produção para o público infantil e infanto-juvenil. A autora escreve há mais de quarenta anos e tem mais de cem livros publicados em 20 diferentes idiomas ${ }^{4}$.

O livro é composto por quatro histórias: Camilão, o comilão; Jeca, o tatu; Dorotéia, a centopeia; e Carneirinho, carneirão. Trata-se de um livro de 62 páginas, capa dura, colorido, com texto e ilustrações a cada página dupla.

Já de início, pode-se perceber que na capa do livro consta apenas a autoria do texto, as informações referentes às ilustrações de Alberto Llinares ${ }^{5}$, são apresentadas apenas na folha de rosto.

Nesta análise, nos restringimos à primeira história "Camilão, o comilão", que trata das andanças de Camilão, um porco grande e comilão

\footnotetext{
${ }^{4}$ Segundo informações colhidas no site da autora: http://www.anamariamachado.com/biografia

${ }^{5}$ Alberto Llinares ilustrou muitas obras, como as de Ana Maria Machado, Ruth Rocha, Naum Alves de Souza e Luiz Galdino.
} 
que, de quando em quando, para na casa de um amigo para pedir um pouco de comida. Mesmo preguiçoso, é muito querido por todos e recebe uma melancia do cachorro, duas abóboras do burro, três queijos e quatro litros de leite da vaca, cinco espigas de milho da galinha e assim sucessivamente. É uma história cumulativa, que brinca com a numeração e a contagem. Ao final, com a cesta cheia de comida, Camilão faz uma festa de comilança e convida todos os seus amigos para participarem.

A relação entre texto e ilustração é disposta de forma bastante tradicional: linearmente, primeiro o texto e em seguida, a imagem que o reproduz. Na primeira página se pode ler:

Camilo era um leitão.

Um porco grande, o Camilão.

Não era um porco dos mais porcos.

Mas era preguiçoso.

E muito guloso.

Um comilão, esse Camilão. (...)

A imagem que se tem na sequência apresenta um porco rosado, grande, devorando um pedaço de bolo. Na página seguinte:

Figura 1: Camilão, o comilão

Um dia Camilão saiu de casa com uma cesta vazia.

E na roça do do seu Manduca, encontrou o cachorro Fiel.

E na roça do seu Manduca, encontrou o cachorro Fie.
- Bom-dia, amigo. Quee que você está fazendo?
- Trabalhando, tomando conta destas melancias.

- Puxa, quanta melancia! E eu aqui com tanta fome que ach

até que vou desmaiar. Será que você podia me arranjar uma? - Está bem. Uma só não faz falta. Tome.

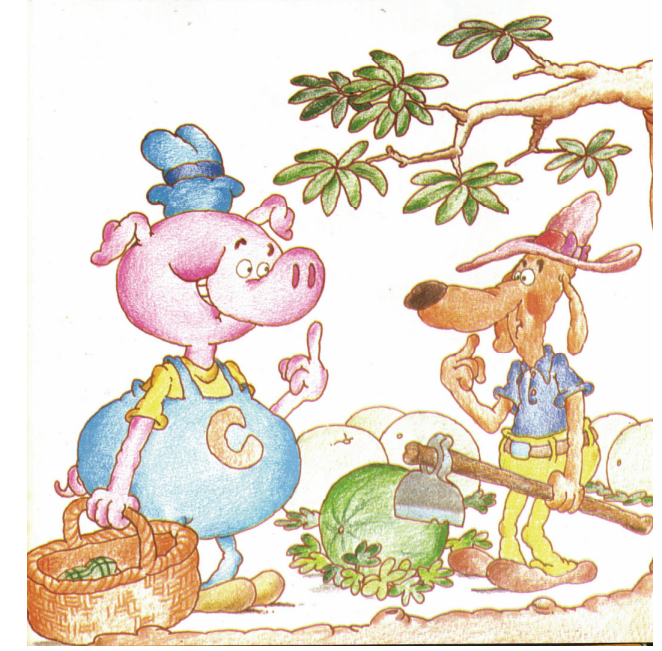

Um dia Camilão saiu de casa com uma cesta vazia.

No fundo, só um guardanapo.

E na roça do seu Manduca, encontrou o cachorro Fiel.

- Bom dia amigo. Que é que você está fazendo?

- Trabalhando, tomando conta dessas melancias.

- Puxa, quanta melancia! E eu aqui com tanta fome que acho até que vou desmaiar. Será que você podia me arranjar uma?

- Está bem. Uma só não faz falta. Tome.

Abaixo do texto, têm-se a reprodução exata em imagens do que foi dito por meio das palavras: Camilão com uma cesta vazia às mãos, em que se pode ver ao fundo um guardanapo verde. Gesticula com o dedo o número um, com um meio sorriso. A roça do seu Manduca está representada pela enxada nas mãos do cachorro fiel.

Não pretendemos avaliar a qualidade das ilustrações, das cores, do traço ou da técnica separadamente, se promovem identificação ao pequeno leitor ou se são agradáveis aos olhos. Nosso intuito é atentar 
para a composição do livro como um todo e as possíveis relações entre texto e imagem.

Ribeiro (2008, p. 133) acredita que essa relação deve ser entendida como uma tradução, tendo em vista

adaptar-se a um sentido a partir da sua transposição a um outro ambiente. Nesse caso, podemos considerar o ilustrador um sujeito que interpreta os signos da palavra e os transporta para outra linguagem. Desse modo, a ilustração deve ser valorizada como uma nova criação e, sendo assim, a ideia de recriação nos possibilita distanciar a ilustração da imitação da palavra e do real.

As imagens, no caso do livro citado, se reduzem a reproduzir o texto escrito em outra linguagem, a visual. Não acrescentam novas informações ao que está dito, não propõem interações ou interpretações além da palavra. O texto funciona de forma independente. Trata-se, portanto, de um livro com ilustração.

Faz-se necessário considerar que a obra analisada é de 1982 e que muitas mudanças e formas de se pensar a ilustração se fizeram de lá para cá ${ }^{6}$. Mais do que uma análise, trata-se de um exercício de comparação e aprofundamento do olhar com o intuito de auxiliar os bibliotecários a manusearem e aproveitarem as potencialidades que o livro ilustrado oferece.

Ler um livro ilustrado é a possibilidade de ir além da separação entre texto e imagem como categorias dissociadas. O livro ilustrado abre a perspectiva de diálogo entre essas duas categorias somadas ao projeto gráfico que o constitui. Acerca disso, Renato Moriconi (apud TAVARES, 2013) afirma: "há no livro ilustrado três línguas diferentes - a palavra, a imagem e o projeto gráfico ou arquitetura do livro - que, se bem usados, fazem dele um belo concerto polifônico, com sons e silêncios próprios".

Tendo em vista a ideia de polifonia como o exercício de diálogo entre a pluralidade de vozes que se manifestam (BAKHTIN, 2013), tomemos outro exemplo, agora de um livro ilustrado:

A obra analisada é "Vizinho, vizinha", com texto de Roger Mello, ilustrado por Graça Lima, Mariana Massarani e com a participação especial de Roger Mello.

Os três autores citados, além de terem seu trabalho amplamente reconhecido como ilustradores, são também escritores. Cabe destacar que Roger Mello foi o primeiro (e único) ilustrador brasileiro a ganhar o prêmio Hans Cristian Andersen ${ }^{7}$ em 2014, considerado o Nobel de Literatura infanto-juvenil, concedido pelo International Board on Books for Young People (IBBY), conselho internacional sobre literatura para os jovens.

O livro tem 36 páginas, formato retangular, é colorido e as imagens predominam sobre o texto em relação à disposição espacial. Há uso de

\footnotetext{
${ }^{6}$ Conforme explicitado nas considerações iniciais deste artigo.

7 Na categoria escritor (a), Ana Maria Machado (2000) e Ligya Bojunga (1982) já foram agraciadas com a premiação.
} 
página dupla com a mesma imagem nas guardas do livro e na primeira página. Os três autores estão citados na capa do livro, sem distinção entre eles.

"Vizinho, vizinha" é uma história sobre a vida nas grandes cidades, em suas possibilidades de encontros e desencontros. No dia a dia no interior de seus apartamentos, o vizinho do 101 já viajou o mundo inteiro, enquanto a vizinha do 102 tem uma estante de livros do tamanho do mundo. Ela nem imagina que ele coleciona discos da velha guarda e que perde a noção das horas quando lê quadrinhos. Ele nem desconfia que ela quer aprender a tocar clarineta e que alimenta um rinoceronte embaixo da pia.

Os encontros casuais no corredor não são suficientes para uma relação genuína entre os dois. Ela só se dá a partir da visita da sobrinha dele e do neto dela que, brincando, podem romper pouco a pouco os limites das paredes e da solidão dos dois personagens. O final deixa a sugestão de uma possível aproximação entre eles.

O texto começa assim:

Quem passa pela Rua do Desassossego, número 38, nem percebe, mas...

Diferentemente do primeiro exemplo, nesta página não há a ilustração de uma rua, uma casa e seu número exposto. Apenas a página com a frase disposta em um fundo amarelo, criando uma expectativa no leitor para o que vem na sequência:

O vizinho do 101 toma café enquanto observa gravuras de bichos. A vizinha do 102 já voltou da maratona.

Figura 2: Vizinho, vizinha

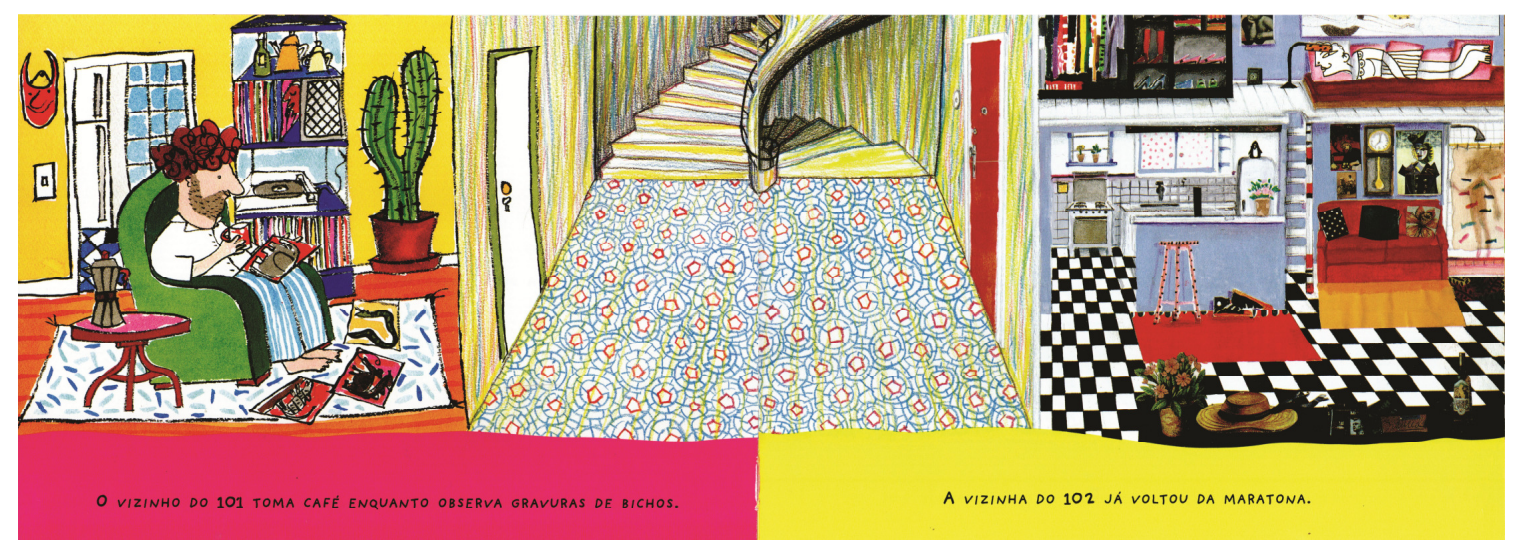

É interessante observar que em vez de um tempo sequencial marcado pelas dobras do livro, a página dupla apresenta a ocorrência de ações simultâneas: enquanto o vizinho toma café, a vizinha toma banho ${ }^{8}$. Entre os dois apartamentos há um corredor, em que no decorrer da narrativa também acontecem ações.

\footnotetext{
8 Pode-se ver no canto direito da imagem (figura 2).
} 
A inovação se apresenta pela proposta editorial da obra com três ilustradores diferentes: Mariana Massarani ilustra o apartamento do vizinho, Graça Lima o da vizinha e Roger Mello o corredor que une os dois.

Toda a história se passa no interior dos apartamentos, que são ilustrados com riqueza de detalhes. Cada apartamento está em uma página do livro. O corredor, ao centro, ocupa um pedaço de cada página.

As cores de fundo do texto reforçam a delimitação do espaço: o rosa trata do cotidiano do vizinho, enquanto o amarelo fala da vizinha. A disposição dos elementos, portanto, está a favor da proposta da história: traz os limites do viver em apartamento também para a forma como o texto é apresentado.

A delimitação do espaço só é quebrada com a brincadeira das crianças que abre possibilidades de os vizinhos ensaiarem uma aproximação. Neste momento, apesar de ainda haver a separação de cores por página, o texto se mistura entre as duas.

\section{Considerações finais}

O livro ilustrado é uma proposta inovadora que exige outras competências, habilidades e atitudes do mediador de leitura.

Por suas especificidades, o livro ilustrado permite uma atenção ao objeto livro em sua plenitude, como objeto artístico. Por ser múltiplo e oferecer diversas possibilidades de interação e leitura, trata-se de excelente instrumento para mediação. É bom lembrar que no livro ilustrado a imagem não é mero apêndice, é também um texto - visual mas paralelo ao verbal. Como tal, permite intercalar ícones e palavras num interlúdio mágico.

A interação com esse material artístico visual oportuniza o diálogo com o leitor. Além disso, pode suscitar conversas, debates e releituras a partir de sua mediação.

Estará o bibliotecário atento a essa questão? Tem se preocupado em acrescentar ao acervo tal material? Empenha-se em realizar leituras do livro ilustrado na Hora do Conto ou em atividades culturais da biblioteca? Percebe as potencialidades que ele enseja?

Muitas vezes tímida, a atuação do bibliotecário pode ser ampliada e desenvolvida em prol da mediação da leitura literária. Considerando que a leitura é algo que nos escapa, Pétit (2013, p. 27) acredita que o que "podem fazer os mediadores de livros é, levar as crianças - e os adultos a uma maior familiaridade, uma maior naturalidade na abordagem dos textos escritos". E com os textos visuais!

\section{Referências}

BAKHTIN, Mikhail. Problemas da poética de Dostoiévski. Rio de Janeiro: Forense Universitária, 2013. 
BORTOLIN, Sueli. Mediação oral da literatura: a voz dos bibliotecários lendo ou narrando. 234 f. 2010. Tese (Doutorado em Ciência da Informação). Universidade Estadual Paulista "Júlio de Mesquita Filho", Marília, 2010.

BRETAS, Maria Luiza Batista. Leitura é fundamental: desafios na formação de jovens leitores. Belo Horizonte: RHJ, 2012.

CALDIN, Clarice Fortkamp. A poética da voz e da letra na literatura infantil: leitura de alguns projetos de contar e ler para crianças. Dissertação (Mestrado em Literatura). Universidade Federal de Santa Catarina, Florianópolis, 2001, p. 29-42.

CALDIN, Clarice Fortkamp. Leitura e literatura infanto-juvenil. Florianópolis: CIN/CED/UFSC, 2010.

COELHO, Nelly Novaes. Literatura infantil: teoria, análise, didática. São Paulo: Moderna, 2000.

DALCIN, Andréa Rodrigues. A leitura do livro ilustrado e livro imagem: da criação ao leitor e suas relações entre texto, imagem e suporte. In: SEMINÁRIO DE PESQUISA EM EDUCAÇÃO DA REGIÃO SUL - ANPED SUL, 9., 2012, Caxias do Sul, RS. Anais... Caxias do Sul, 2012. Disponível em:

<http://www.portalanpedsul.com.br/admin/uploads/2012/Alfabetizacao,_ Leitura_e_Escrita/Trabalho/05_07_46_2783-6605-1-PB.pdf>. Acesso em: fev. 2016.

GILI, Silvana. Livros ilustrados: textos e imagens. 102 p. 2014. Dissertação (Mestrado em Literatura). Universidade Federal de Santa Catarina, Florianópolis, 2014.

HUNT, Peter. Crítica, teoria e literatura infantil. São Paulo: Cosac Naify, 2010.

LINS, Guto. Livro infantil? : projeto gráfico, metodologia, subjetividade. São Paulo: Rosari, 2002.

MACHADO, Ana Maria. Camilão, o comilão. In: Ilustração: Llinares. São Paulo: Abril Cultural, 1982.

Histórias de recreio.

MARTINS, Ana Amélia Lage. Mediação e bibliotecas públicas: uma perspectiva dialética. Perspectivas em Ciência da Informação, v. 19, no. spe., out./dez. 2014.

MEIRELES, Cecília. Problemas da literatura infantil. Rio de Janeiro: Nova Fronteira, 1984.

MELLO, Roger. Vizinho, vizinha. Ilustrações: Graça Lima, Mariana Massarani e participação especial de Roger Mello. São Paulo: Cia das letrinhas, 2002.

NIKOLAJEVA, Maria e SCOTT, Carole. Livro ilustrado: palavras e imagens.

São Paulo: Cosac Naify, 2011.

PALO, Maria José; OLIVEIRA, Maria Rosa D. Literatura infantil: voz de criança. 3. ed. São Paulo: Ática, 1998. 
PÉTIT, Michèle. Leituras: do espaço íntimo ao espaço público. São Paulo: Ed. 34, 2013

RASTELI, Alessandro; CAVALCANTE Lídia Eugênia. A competência em informação e o bibliotecário mediador da leitura em Biblioteca Pública. Encontros Bibli: Revista Eletrônica de Biblioteconomia e Ciência da Informação, v. 18, n. 36, 2013.

RIBEIRO, Marcelo. A relação entre o texto e a imagem. In: OLIVEIRA, Ieda (Org.). O que é qualidade em ilustração no livro infantil e juvenil: com a palavra o ilustrador. São Paulo: DCL, 2008.

TAVARES, Cris. Literatura infantil é, antes de tudo, literatura. Revista Emília, out. 2011.2 Disponível em: http://revistaemilia.com.br/mostra.php?id=74\#adelia. Acesso em: dez. 2014. TAVARES, Cris. Livro ilustrado: um "concerto polifônico" para deleite do leitor. Revista Emília, ago. 2013. Disponível em: http://www.revistaemilia.com.br/mostra.php?id=336. Acesso em: dez. 2014.

VAN DER LINDEN, Sophie. Para ler o livro ilustrado. São Paulo: Cosac Naify, 2011. 